\title{
Synthesis of carboxamides tranylcypromine analogues as LSD1 (KDM1A) inhibitors for AML
}

\author{
Maria Teresa Borrello, ${ }^{\dagger}$ Hanae Benelkebir, ${ }^{\dagger}$ Chak Hin Tam, ${ }^{\dagger}$ Manar Shafat, ${ }^{\ddagger}$ Stuart A. Rushworth, ${ }^{\ddagger}$ \\ Kristian M. Bowles, `Leon Douglas, Patrick J. Duriez, "Sarah Bailey, " Simon J. Crabb, " Graham Pack- \\ ham, "A. Ganesan*,†
}

'School of Pharmacy and ${ }^{\dagger}$ Norwich Medical School, University of East Anglia, Norwich Research Park Norwich NR47TJ, United Kingdom ${ }^{\S}$ Centre de Recherche en Cancérologie de Marseille (CRCM), INSERM U1068, CNRS UMR 7258, AixMarseille Université and Institut Paoli-Calmettes, Parc Scientifique et Technologique de Luminy, 163 Avenue de Luminy, 13288 Marseille, France

"Protein Core Facility and Cancer Sciences, Cancer Research UK Centre and Experimental Cancer Medicines Centre, University of Southampton, Southampton General Hospital, Southampton SO16 6YD, United Kingdom

KEYWORDS: LSD, KDM1A, small molecules inhibitors, Epigenetic, Acute myeloid leukaemia.

\begin{abstract}
Lysine-specific demethylase 1 (LSD1/KDM1A) oxidatively removes methyl groups from histone proteins and its aberrant activity has been correlated with cancers including acute myeloid leukemia (AML). We report a novel series of tranylcypromine analogues containing a carboxamide at the 4-position of the aryl ring and novel carbamates. These compounds were potent submicromolar LSD1 inhibitors in enzyme assays and were anti-proliferative against a panel of AML cell lines. LSD1 target engagement in cells was demonstrated through the effects on $\mathrm{H} 3 \mathrm{~K} 4 \mathrm{me} 2$ protein expression, CD86, CD11b and CD14 levels.
\end{abstract}

Lysine residues in proteins undergo a variety of epigenetic post-translational modifications through alkylation and acylation. ${ }^{1}$ Alkylation involves the addition of one, two or three methyl groups catalysed by lysine methyltransferases (KMTs) and is dynamically reversible by the action of lysine demethylases (KDMs). The KDMs, approximately twenty-five in number in humans, are further subdivided into KDM1-7 based on catalytic mechanism. ${ }^{2}$ KDM1 or lysine-specific demethylase was the first demethylase to be discovered in 2004 and comprises two isoforms LSD1 and LSD2, also known as KDM1A and KDM1B respectively. The LSDs are flavin-dependent enzymes that utilize the FAD cofactor for oxidation while the remaining KDMs 2-7, also known as Jumonji C (JmjC) demethylases, are mechanistically distinct 2-oxoglutarate and iron(II)-dependent dioxygenases. Regardless of the mechanism, all KDMs oxidize the methyl group to a carbinolamine that undergoes spontaneous hydrolysis to formaldehyde and the demethylated lysine product.

In addition to its catalytic amine oxidase subunit, LSD1 contains protein-protein interaction domains that promote its association with a variety of binding partners. Through the resulting multi-protein complexes, LSD1 demethylates the nucleosome at histone $\mathrm{H} 3 \mathrm{~K} 4, \mathrm{H} 3 \mathrm{~K} 9$ and $\mathrm{H} 4 \mathrm{~K} 20$ residues. LSD1 has an activating or repressive effect on transcription depending on the context. ${ }^{3,4} \mathrm{H} 3 \mathrm{~K} 4$ demethylation is associated with gene silencing and the maintenance of leukemic stem cells in an undifferentiated and proliferative state. Meanwhile, association with androgen or oestrogen receptors promotes H3K9 demethylation and drives hormone-dependent gene transcription that promotes cell proliferation. Moreover, the enzyme's high expression in sarcomas, neuroblastoma, bladder, gastric and lung cancer point out LSD1 as a target for cancer chemotherapy. Both the reversible and irreversible inhibition of LSD1 can be accomplished by a diverse set of small molecule scaffolds. ${ }^{5-7}$ A particularly successful approach has taken advantage of LSD1's homology with other FAD-dependent amine oxidases that are well-established therapeutic targets. Some monoamine oxidase (MAO) inhibitors also inhibit LSD1, among which the most important is the approved drug $( \pm)$-tranylcypromine $(\mathbf{1}) .{ }^{8}$ Tranylcypromine binds reversibly to the LSD1 or MAO active site and transfers a single electron to the FAD cofactor. The resulting radical cation 2 rapidly undergoes strain induced ring opening to generate reactive intermediate 3 which covalently modifies FAD and irreversibly inactivates the enzyme. The LSD1 inhibitory activity of tranylcypromine has led to reinvestigation of the drug in cancer clinical trials as well as the synthesis of second-generation analogues to improve target affinity. ${ }^{9-14}$ One class of tranylcypromine analogues 4 (Figure 2) reported by $\mathrm{Mai}^{15-19}$ and Takeda $^{20,21}$ feature a 4-anilinoamide substituent display high activity with examples that are submicromolar LSD1 inhibitors. Our interest lay in exploring the analogous 'reverse amide' isosteres $\mathbf{5}$ that would potentially avoid toxicity issues due to hydrolysis of the aniline amide. While our studies were in progress, a patent by Takeda also disclosed reverse amide structures. ${ }^{22}$ Nevertheless, only compound $\mathbf{5 a}$ below was described in the patent and the rest are unique to this work.

\section{RESULTS AND DISCUSSION}

Chemical synthesis. A number of methods have been reported for the generation of the tranylcypromine scaffold. The most popular sequence involves the synthesis of a cyclopropane 
carboxylic acid that is converted to the amine by a Curtius rearrangement. The precursor cyclopropane carboxylic acid is assembled in $[2+1]$ fashion employing either the union of a styrene and a carbenoid or a cinnamate and a carbanion. In our synthesis, we selected the cinnamate route starting with 4formylbenzaldehyde (6, Scheme 1). Protection as the methyl ester 7 and a Horner-Wadsworth-Emmons olefination with tbutyl diethylphosphonoacetate provided the differentially protected cinnamate diester 8. ${ }^{23,24}$ A Johnson-Corey-Chaykovsky cyclopropanation installed the three member ring in 9 with the trans configuration as confirmed by the ${ }^{1} \mathrm{H}-{ }^{1} \mathrm{H}$ coupling constants of the cyclopropyl moiety $\left(J_{\mathrm{ab}}=4.2-4.5 \mathrm{~Hz}\right)$. Selective acidic removal of the tert-butyl ester afforded the monoacid $\mathbf{1 0}$ which was reacted with diphenylphosphoryl azide followed by Curtius rearrangement and trapping of the resulting isocyanate with tert-butanol to give Boc carbamate 11. The methyl ester was then hydrolysed to give the common intermediate 12 which was coupled with diverse primary and secondary amines. Boc deprotection of the resulting amides $13 \mathbf{a}-\mathbf{r}$ completed the synthesis of the desired tranylcypromine analogues $( \pm)$ 5a-r. LSD1 enzyme assays and AML cell growth inhibition. We performed a fluorescence-based LSD1 enzymatic assay using a synthetic histone $\mathrm{H} 3$ peptide dimethylated at $\mathrm{K} 4$ as substrate and AmplexRed ${ }^{\circledR}$ detection of the $\mathrm{H}_{2} \mathrm{O}_{2}$ byproduct according to our previously published procedure. ${ }^{25}$ The results (Table 1) confirmed that all the analogues were significantly superior to tranylcypromine as LSD1 inhibitors with the exception of $\mathbf{5 g}$ and $\mathbf{5 i}$. Compounds $\mathbf{5 a - c}$ containing an aryl or heteroaryl substituent linked by a one or two carbon spacer to the carboxamide were submicromolar inhibitors of the enzyme. Furthermore, this was achieved with simple low MW amides, unlike the more elaborate substitution observed with potent examples of the earlier reverse amide series 4 . Switching to the non-aromatic cyclohexyl isosteres $\mathbf{5 d}-\mathbf{e}$ led to a loss of activity suggesting that $\pi-\pi$ interactions might be important within the enzyme active site. In the benzyl compound $\mathbf{5 a}$, para substitution as in $\mathbf{5 f}-\mathbf{5 j}$ led to reduced activity, most dramatically with the bromo and methoxy analogues. We additionally synthesized the tertiary amides $\mathbf{5 l}$ with a dibenzyl group and $\mathbf{5 m}-\mathbf{5 r}$ containing a 4-aminopiperazine moiety. The tertiary amides, however, did not exhibit any gain in potency compared to the simpler secondary amides.

The most active analogues were tested for their growth inhibitory effects against the Kasumi-1 and MV4-11 AML cell lines. After $72 \mathrm{~h}$ treatment, the analogues typically arrested cell proliferation at submicromolar concentrations (Table 2). The rank order in the enzyme and cell-based assay had some differences that are likely to reflect changes in lipophilicity and cell uptake. The most active compounds were tested in additional AML cell lines. Overall, analogues 5a-c exhibited a combination of submicromolar potency in both enzyme and growth inhibition assays and were selected for further profiling.

Mechanistic and target engagement studies. We verified that analogues 5a-c, like tranylcypromine, act by an irreversible mechanism of action through a washout experiment. ${ }^{26}$ Cells were treated with the analogues for a period of $6 \mathrm{~h}$ after which the medium containing the drug was washed out and replaced by inhibitor-free medium. Following $72 \mathrm{~h}$ incubation, survival rates of the samples exposed to the drugs for this short time course were compared with the effect of continuous drug treatment. The analysis revealed that the antiproliferative effects were maintained, confirming irreversible inhibition that was unaffected by the drug washout (Figure 3).

To demonstrate LSD1 target engagement, we investigated the effects of inhibitors on H3K4 methylation levels. Kasumi-1 cells were incubated with $\mathbf{5 b}(200 \mathrm{nM})$ for various time courses (2, 4, 6, 48 and $72 \mathrm{~h}$ ). After 48 and $72 \mathrm{~h}$ we observed a time dependent selective increase of $\mathrm{H} 3 \mathrm{~K} 4$ dimethylation whereas shorter time points showed a less pronounced increase of this biomarker (Figure 4). Further evidence for target engagement came from the reactivation of myeloid-differentiation associated cell surface cluster of differentiation proteins CD86, CD1 $1 \mathrm{~b}$ and CD14. CD86, a linker of the co-inhibitory immune response of the CTL4 and CD28 receptor, is among the most highly upregulated genes following LSD1 inhibition and a convenient biomarker. ${ }^{27,28}$ The selected inhibitors $5 \mathbf{a}-\mathbf{c}(200 \mathrm{nM})$ were incubated with AML cell lines for $72 \mathrm{~h}$ and found to have a significant effect on the expression of CD86 (Figure 5). In addition, we examined the levels of CD11b and CD14, glycoproteins on the myeloid cell surface that are exclusively expressed in mature leucocytes and not in undifferentiated cells. ${ }^{29}$ As anticipated, the LSD1 inhibitors triggered cell differentiation as confirmed by increased CD11b and CD14 expression in AML derived cell lines after $48 \mathrm{~h}$ of treatment (Figure 6-7).

\section{CONCLUSIONS}

A series of tranylcypromine analogues containing a carboxamide substituent at the para position of the phenyl ring were synthesized. These compounds are reverse amide isosteres of previous LSD1 inhibitors and our results demonstrate that the new analogues retain potent enzyme inhibition. Analogues 5ac were submicromolar inhibitors of cell proliferation against a panel of AML cell lines. Mechanistic studies indicate these tranylcypromine analogues are irreversible in action and exhibit the biomarker profile expected for LSD1 inhibition viz. increased $\mathrm{H} 3 \mathrm{~K} 4 \mathrm{me} 2$ levels and expression of CD86, CD11b and CD14.

\section{EXPERIMENTAL SECTION}

Chemistry. General procedures. All chemicals were purchased from Sigma Aldrich, Lancaster Synthesis GmbH, Alfa Aesar, and Novabiochem and used without further purification. Flash chromatography TLC was used to monitor the reaction and performed on aluminium-backed silica gel coated plates (Merck DC, Alufolien Kieselgel $60 \mathrm{~F}_{254}$ ) with spots visualized by UV-light ( $\lambda 254 \mathrm{~nm}$ ). Product concentration after reactions and extractions involved the use of a rotary evaporator operating at reduced pressure of ca. 20 Torr and the term in vacuo refers to solvent concentration at reduced pressure. When necessary products were purified by flash chromatography using silica gel (MN Kieselgel 60, 40-63 $\mu \mathrm{m}, 230-400$ mesh ASTM). NMR spectra were recorded on a Bruker AC 400 spectrometer and the spectra were calibrated to the residual deuterated solvent peak $\left(\mathrm{CDCl}_{3}, \mathrm{CD}_{3} \mathrm{OD}\right.$ or DMSO-d6). The chemical shifts are reported in $\delta(\mathrm{ppm})$ units followed by brackets for protons containing spectral details in this order: multiplicity (s: singlet, $\mathrm{d}$ : doublet, t: triplet, q: quartet, m: multiplet, br: broad), coupling constants (reported in $\mathrm{Hz}$ ), number of protons (from integration). HRMS were acquired through the EPSRC National Mass Spectrometry Service Centre, Swansea. Melting points were determined with a STUART Melting point SMP10. IR spectra were determined with Perkin Elmer, Spectrum GX, FT- 
IR system. RP-HPLC analyses were performed with an Agilent Technologies 1200 series chromatograph with an Agilent Technologies ZORBAX Eclipse XDB-C18 $(5 \mu \mathrm{m}, 4.6 \times 150 \mathrm{~mm})$ column. Gradient used: 95:5 water: methanol with $0.05 \%$ TFA additive to 5:95 water: methanol over 15 min returning to $95: 5$ water: methanol over $5 \mathrm{~min}$ at a flow rate of $1 \mathrm{~mL} / \mathrm{min}$. Complete characterisation was carried out on all final compounds. Purity was monitored at $220 \mathrm{~nm}$ and found to be at least $95 \%$ for all compounds that were tested in biological assays.

( \pm )-trans-4-methyl[2-(tert-butoxycarbonyl) cyclopropyl)]benzoate (9).

Trimethylsulfoxonium iodide ( $15 \mathrm{~g}, 68.1 \mathrm{mmol}, 1.2$ equiv.) was added in small portions to a suspension of $\mathrm{NaH}(2.27 \mathrm{~g}, 68.1$ mmol, $60 \mathrm{wt} \%$ in mineral oil, 1.21 equiv.) in dry DMSO (60 $\mathrm{mL})$. The solution was stirred for $45 \mathrm{~min}$. The olefin 8 (14.9 g, $56.8 \mathrm{mmol}, 1$ equiv.) dissolved in DMSO $(60 \mathrm{~mL})$, was then added dropwise to the formed ylide and the reaction stirred overnight at rt. After completion, the reaction mixture was poured into iced water $(100 \mathrm{~mL})$ and extracted with EtOAc $(70$ $\mathrm{mL} \times 10)$. The organic phases $(700 \mathrm{~mL})$ were combined and washed with sat. NaHCO3 (200 mL), H2O (200 mL) and brine $(200 \mathrm{~mL})$ and dried over MgSO4. Purification of the crude yellow oil by silica gel column chromatography (petroleum ether/ EtOAc 8.9:1.9) afforded $11(3.7 \mathrm{~g}, 23 \%)$ as a white crystalline solid; $\mathrm{R}_{f}=0.66$ (petroleum ether /EtOAc 8:2); mp $40{ }^{\circ} \mathrm{C}$; IR $1715,1609, \mathrm{~cm}^{-1} ;{ }^{1} \mathrm{H}$ NMR $\left(\mathrm{CDCl}_{3}, 400 \mathrm{MHz}\right) \delta: 1.26$ (ddd, $J=4.8,6.4,8.5 \mathrm{~Hz}, 1 \mathrm{H}), 1.46(\mathrm{~s}, 9 \mathrm{H}), 1.57$ (m, 1H), 1.88 (ddd, $J=4.4,5.5,8.6 \mathrm{~Hz}, 1 \mathrm{H}), 2.4$ (ddd, $J=4.1,5.4,9.5 \mathrm{~Hz}, 1 \mathrm{H}), 3.9$ (s, 3H), $7.1(\mathrm{~d}, J=8.3 \mathrm{~Hz}, 2 \mathrm{H}), 7.9(\mathrm{~d}, J=8.4 \mathrm{~Hz}, 2 \mathrm{H}) ;{ }^{13} \mathrm{C}$ NMR $\left(\mathrm{CDCl}_{3}, 100 \mathrm{MHz}\right) \delta 16.5,24.6,24.8,27.1,50.9,79.8,124.9$, 127.6, 128.7, 145.07, 165.8, 171.0; HRMS (ESI) m/z calcd. for $\mathrm{C}_{16} \mathrm{H}_{24} \mathrm{O}_{4} \mathrm{~N}\left[\mathrm{M}+\mathrm{NH}_{4}\right]^{+}$294.1700, found 294.1704.

\section{$( \pm)$-trans-[2-(4-}

(methoxycarbonyl)phenyl]cyclopropanecarboxylic acid (10).

Trifluoroacetic acid (19.7 g, $13.2 \mathrm{~mL}, 0.17 \mathrm{~mol}, 13$ equiv.) and triethylsilane (3.86 g, $5.3 \mathrm{~mL}, 33.25 \mathrm{mmol}, 2.5$ equiv.) were added to a solution of 8 (3.7 g, $13.4 \mathrm{mmol})$ in DCM $(40 \mathrm{~mL})$. The reaction mixture was stirred at $\mathrm{rt}$ and monitored by TLC. After completion, the reaction mixture was co-evaporated with acetonitrile $(15 \mathrm{~mL} \times 3)$ to give $\mathbf{1 0}(2.1 \mathrm{~g}, 72 \%)$ as a white crystalline solid that was used without further purification: mp 123 ${ }^{\circ} \mathrm{C}$; IR 3307, 1716, 1608, 1476.5, cm-1; ${ }^{1} \mathrm{H}$ NMR $\left(\mathrm{CD}_{3} \mathrm{OD}, 400\right.$ MHz) $\delta 1.43$ (ddd, $J=4.6,6.5,8.5 \mathrm{~Hz}, 1 \mathrm{H}$ ), 1.60 (ddd, $J=4.6$, $5.3,9.4 \mathrm{~Hz}, 1 \mathrm{H}), 1.92(\mathrm{ddd}, J=4.1,5.4,8.5 \mathrm{~Hz}, 1 \mathrm{H}), 2.51$ (ddd, $J=4.0,6.3,9.2 \mathrm{~Hz}, 1 \mathrm{H}), 3.90(\mathrm{~s}, 3 \mathrm{H}), 7.25$ (d, $J=8.4 \mathrm{~Hz}, 2 \mathrm{H})$, $7.93(\mathrm{~d}, J=8.44 \mathrm{~Hz}, 2 \mathrm{H}) ;{ }^{13} \mathrm{C} \mathrm{NMR}\left(\mathrm{CD}_{3} \mathrm{OD}, 100 \mathrm{MHz},\right) \delta 17.9$, 25.6, 26.9, 52.5, 127.1, 129.4, 130.7, 147.6, 168.7, 176.4; HRMS (ESI) $m / z$ calcd. for $\mathrm{C}_{12} \mathrm{H}_{11} \mathrm{O}_{4}[\mathrm{M}-\mathrm{H}]^{-} 219.0663$, found 219.0659 .

$( \pm)$-trans-4-methyl-2-[(tertbutoxycarbonyl)amino]cyclopropyl benzoate (11).

The acid 12 (2.1 g, 9.5 mmol, 1.0 equiv.), diphenylphosphoryl azide (2.86 g, $2.27 \mathrm{~mL}, 10.5 \mathrm{mmol}$, 1.1 equiv.) and triethylamine (1.44 g, $1.98 \mathrm{~mL}, 14.3 \mathrm{mmol}$, 1.5 equiv.) were combined in tert-butanol $(11 \mathrm{~mL})$ under argon, heated at reflux and allowed to react for $72 \mathrm{~h}$. After that time, the reaction mixture was cooled to rt, diluted with EtOAc (20 $\mathrm{mL}$ ) and washed with saturated $\mathrm{Na}_{2} \mathrm{CO}_{3}$ solution $(20 \mathrm{~mL} \times 3)$. The organic layer was separated and the aqueous layer further extracted with EtOAc $(20 \mathrm{~mL})$. The organic layers were combined $(40 \mathrm{~mL})$, washed with sat. $\mathrm{NaHCO}_{3}(10 \mathrm{~mL}), \mathrm{H}_{2} \mathrm{O}(10$
$\mathrm{mL})$ and brine $(10 \mathrm{~mL})$ and dried over $\mathrm{MgSO}_{4}$. Concentration in vacuo afforded a yellow oil which was purified by silica gel column chromatography (Hexane/EtOAc 8:2) affording 11 (1.6 $\mathrm{g}, 42 \%$ ) as a white crystalline solid: $\mathrm{R}_{f}=0.57$ (Hexane /EtOAc 8:2); mp $45{ }^{\circ} \mathrm{C} ;{ }^{1} \mathrm{H}$ NMR $\left(\mathrm{CDCl}_{3}, 400 \mathrm{MHz}\right) \delta 1.20-1.24(\mathrm{~m}$, $2 \mathrm{H}), 1.43(\mathrm{~s}, 9 \mathrm{H}), 2.07(\mathrm{td}, J=3.1,7.6 \mathrm{~Hz}, 1 \mathrm{H}), 2.70-2.78(\mathrm{~m}$, 1H) $3.9,(\mathrm{~s}, 3 \mathrm{H}), 7.15(\mathrm{~d}, J=8.5 \mathrm{~Hz}, 2 \mathrm{H}), 7.9(\mathrm{~d}, J=8.4 \mathrm{~Hz}, 2 \mathrm{H})$; ${ }^{13} \mathrm{C} \mathrm{NMR}\left(\mathrm{CDCl}_{3}, 100 \mathrm{MHz}\right) \delta 14.8,26.3,28.0,28.1,28.4,55.3$, $113.8,127.8,130.6,132.7,157.9 ; 168.7$; HRMS (ESI) $\mathrm{m} / z$ calcd. for $\mathrm{C}_{15} \mathrm{H}_{18} \mathrm{~N}_{1} \mathrm{O}_{4}[\mathrm{M}-\mathrm{H}]^{-} 276.1241$, found 276.1243.

( \pm -trans-4-2-[(tert-butoxycarbonyl) amino)cyclopropyl]benzoic acid (12).

To a suspension of 11 (1.6 g, $5.7 \mathrm{mmol}, 1$ equiv.) in THF: $\mathrm{H}_{2} \mathrm{O}$ : (3:1 ratio), LiOH ( $0.4 \mathrm{~g}, 17.32$ mmol, 3 equiv.) was added and the reaction mixture heated to $50{ }^{\circ} \mathrm{C}$ and stirred for 3 h. The reaction progress was monitored by TLC and after completion, the reaction mixture was diluted with water (10 $\mathrm{mL}$ ) and acidified to $\mathrm{pH} \mathrm{1-2} \mathrm{with} \mathrm{sat.} \mathrm{KHSO}_{4}$. The aqueous layer was extracted with EtOAc $(20 \mathrm{~mL} \times 3)$ and the combined organic layers $(60 \mathrm{~mL})$ were washed with sat. $\mathrm{NaHCO}_{3}(10 \mathrm{~mL})$, $\mathrm{H}_{2} \mathrm{O}(10 \mathrm{~mL})$ and brine $\mathrm{H}_{2} \mathrm{O}(10 \mathrm{~mL})$ and dried over $\mathrm{MgSO}_{4}$. Solvent concentration in vacuo afforded $12(1.3 \mathrm{~g}, 82 \%)$ as a white solid that was used without further purification. IR 3314, 2873, 1681, $1453 \mathrm{~cm}^{-1} ;{ }^{1} \mathrm{H}$ NMR $\left(\mathrm{CD}_{3} \mathrm{OD}, 400 \mathrm{MHz}\right) \delta 1.21-$ $1.25(\mathrm{~m}, 1 \mathrm{H}), 1.43(\mathrm{~s}, 9 \mathrm{H}), 2.04(\mathrm{td}, J=3.9,7.9 \mathrm{~Hz}, 1 \mathrm{H}), 2.69-$ $2.65(\mathrm{~m}, 1 \mathrm{H}), 7.19(\mathrm{~d}, J=8.3 \mathrm{~Hz}, 2 \mathrm{H}), 7.91(\mathrm{~d}, J=8.3 \mathrm{~Hz}, 2 \mathrm{H})$; ${ }^{13} \mathrm{C}$ NMR $\left(\mathrm{CD}_{3} \mathrm{OD}, 100 \mathrm{MHz}\right) \delta 17.1,25.8,28.7,35.0,80.3$, 126.9, 129.4, 130.7, 148.5, 158.9, 169.9; HRMS (ESI) $m / z$ calcd. for $\mathrm{C}_{17} \mathrm{H}_{25} \mathrm{NO}_{4}[\mathrm{M}+\mathrm{H}]^{+} 273.1961$, found 273.1962.

Amide coupling (13a-r) and Boc deprotection (5a-r).

To a stirring suspension of $\mathbf{1 2}$ in DCM, 2 equiv. of DIPEA were added and the mixture stirred until obtaining a clear solution. Subsequently, HOBt (0.2 equiv.) and EDCI (1.5 equiv.) were added and stirred for $30 \mathrm{~min}$. The desired amine was added to the stirring mixture and the reaction mixture further stirred at rt overnight. After that time, the reaction mixture was diluted with DCM and washed with $2 \mathrm{~N} \mathrm{HCl}$ and $1 \mathrm{~N} \mathrm{NaOH}$. The organic layers were combined, washed with sat. $\mathrm{NaHCO}_{3}, \mathrm{H}_{2} \mathrm{O}$ and brine and dried over $\mathrm{MgSO}_{4}$. Concentration in vacuo afforded amides 13a-r. Acid hydrolysis to remove the Boc protecting group was carried out by stirring the carbamate in 0.5 $\mathrm{mL}$ of THF and $0.5 \mathrm{~mL}$ of $4 \mathrm{M} \mathrm{HCl}$ in 1,4 dioxane at rt overnight to give amines $\mathbf{5 a - r}$.

4-(( \pm -trans-2- aminocyclopropyl)- $\mathrm{N}$-benzylbenzamide hydrochloride (5a). Yield 71\%, yellow crystalline solid; mp $200{ }^{\circ} \mathrm{C}$; IR 3336, 3289, 3075, 1674, $1437 \mathrm{~cm}^{-1}$; ${ }^{1} \mathrm{H}$ NMR $\left(\mathrm{CD}_{3} \mathrm{OD}\right) \delta 1.36-1.42(\mathrm{~m}, 1 \mathrm{H}), 1.46-1.51(\mathrm{~m}, 1 \mathrm{H}), 2.46(\mathrm{ddd}$, $J=3.3,6.6,9.9 \mathrm{~Hz}, 1 \mathrm{H}), 2.90-2.92,(\mathrm{~m}, 1 \mathrm{H}), 4.6$ (s, 2H), 7.11$7.19(\mathrm{~m}, 3 \mathrm{H}), 7.22-7.35(\mathrm{~m}, 4 \mathrm{H}), 7.81(\mathrm{~d}, J=8.2 \mathrm{~Hz}, 2 \mathrm{H}) ;{ }^{13} \mathrm{C}$ NMR $\left(\mathrm{CD}_{3} \mathrm{OD}\right) \delta 14.3,22.4,32.2,44.4,127.5,128.2$, 128.5,129.7, 129.5, 134.1, 140.2, 143.9, 169.6; HRMS (ESI) $m / z$ calcd. for $\mathrm{C}_{17} \mathrm{H}_{19} \mathrm{~N}_{2} \mathrm{O}_{1}[\mathrm{M}+\mathrm{H}]^{+} 267.1492$, found 267.1495.

4-( \pm -trans -2-aminocyclopropyl)- $N$-phenethylbenzamide hydrochloride (5b). Yield $67 \%$, yellow solid; mp $180{ }^{\circ} \mathrm{C}$; IR $3283,1637,1545 \mathrm{~cm}^{-1},{ }^{1} \mathrm{HNMR}\left(\mathrm{CD}_{3} \mathrm{OD}\right) \delta 1.36-1.42(\mathrm{~m}, 1 \mathrm{H})$, 1.48 (ddd, $J=4.2,6.7,10.31 \mathrm{H}), 2.42$ (ddd, $J=3.5,6.3 \mathrm{~Hz}, 10.3$ 1H), 2.90 (t, $J=7.7 \mathrm{~Hz}, 3 \mathrm{H}), 3.58(\mathrm{t}, J=7.2 \mathrm{~Hz}, 2 \mathrm{H}), 7.17-7.20$ $(\mathrm{m}, 1 \mathrm{H}), 7.24-7.29(\mathrm{~m}, 6 \mathrm{H}) 7.72(\mathrm{~d}, J=7.7 \mathrm{~Hz}, 2 \mathrm{H}) ;{ }^{13} \mathrm{CNMR}$ $\left(\mathrm{CD}_{3} \mathrm{OD}\right) \delta 14.3,22.4,32.3,36.3,42.6,127.3,127.4,128.6$, 129.5, 129.9, 134.3, 140.6, 143.8, 169.7; HRMS (ESI) $\mathrm{m} / z$ calcd. for $\mathrm{C}_{18} \mathrm{H}_{21} \mathrm{~N}_{2} \mathrm{O}[\mathrm{M}+\mathrm{H}]^{+} 281.1648$, found 281.1648. 
4-( \pm )-trans -2-aminocyclopropyl)- $N$-(2-(thiophen-2yl)ethyl)benzamide hydrochloride (5c). Yield $47 \%$, yellow solid; mp $218{ }^{\circ} \mathrm{C}$; IR 3318, 2775, 2977, $1626,1505 \mathrm{~cm}^{-1} ;{ }^{1} \mathrm{H}$ NMR $\left(\mathrm{CD}_{3} \mathrm{OD}\right) \delta 1.37-1.42(\mathrm{~m}, 1 \mathrm{H}), 1.48$ (ddd, $J=4.56,6.7$, $10.2 \mathrm{~Hz}, 1 \mathrm{H}), 2.43$ (ddd, $J=3.6,6.0,9.0 \mathrm{~Hz}, 1 \mathrm{H}), 2.90-2.94$ (m, $1 \mathrm{H}), 3.13(\mathrm{t}, J=7.0 \mathrm{~Hz}, 2 \mathrm{H}), 3.61(\mathrm{t}, J=7.0 \mathrm{~Hz}, 2 \mathrm{H}), 6.88$ (dd, $J=1.0,3.4 \mathrm{~Hz}, 1 \mathrm{H}), 6.91-6.94(\mathrm{~m}, 1 \mathrm{H}) 7.20(\mathrm{dd}, J=1.0,4.8 \mathrm{~Hz}$, $1 \mathrm{H}), 7.25$ (d, $J=8.4 \mathrm{~Hz}, 2 \mathrm{H}), 7.75$ (d, $J=8.4 \mathrm{~Hz}, 2 \mathrm{H}) ;{ }^{13} \mathrm{C} \mathrm{NMR}$ $\left(\mathrm{CD}_{3} \mathrm{OD}\right) \delta 14.3,22.4,30.1,32.2,42.7,124.7,126.3,127.4$, $127.8,128.6,134.1,142.5,143.7,169.7$.

4-( \pm )-trans-2-aminocyclopropyl)- $N$-(cyclohexylmethyl)benzamide hydrochloride (5d). Yield 58\%, yellow solid; $\mathrm{mp} 198{ }^{\circ} \mathrm{C}$; IR 3335, 1712, $1696,1459 \mathrm{~cm}^{-1} ;{ }^{1} \mathrm{H}$ NMR $\left(\mathrm{CD}_{3} \mathrm{OD}\right.$, $400 \mathrm{MHz}), \delta$ 0.94-1.03 (m, 2H), 1.18-1.31 (m, 4H), 1.33-1.44 (m, 1H), 1.48-1.52 (m, 1H), 1.58-1.69 (m, 2H), 1.71-1.82 (m, 3H), 2.41-2.49 (m, 1H), 2.88-2.92 (m, 1H) 3.20 (d, $J=6.9 \mathrm{~Hz}$, 2H), 7.26 (d, $J=8.2 \mathrm{~Hz}, 2 \mathrm{H}), 7.76(\mathrm{~d}, J=8.2 \mathrm{~Hz}, 2 \mathrm{H}) ;{ }^{13} \mathrm{C} \mathrm{NMR}$ $\left(\mathrm{CD}_{3} \mathrm{OD}, 100 \mathrm{MHz}\right) \delta 14.3,22.4,26.9,27.6,32.3,39.2,39.4$, 47.2, 127.4, 128.6, 134.3, 143.6, 169.8; HRMS (ESI) $\mathrm{m} / \mathrm{z}$ calcd. for $\mathrm{C}_{17} \mathrm{H}_{25} \mathrm{~N}_{2} \mathrm{O}[\mathrm{M}+\mathrm{H}]^{+}, 273.1961$, found 273.1962.

4-( \pm )-trans-2-aminocyclopropyl)- $N$-(2-cyclohexylethyl)benzamide hydrochloride (5e). Yield 33\%, yellow solid; mp 79 ${ }^{\circ} \mathrm{C}$; IR 3318, 1632, 1539, $1449 \mathrm{~cm}^{-1}$; ${ }^{1} \mathrm{HNMR}$ (DMSO-d6, 400 MHz) $\delta$ 0.84-0.96 (m, 2H), 1.08-1.31 (m, 5H), 1.36-1.44 (m, $2 \mathrm{H}), 1.45-1.51(\mathrm{~m}, 1 \mathrm{H}), 1.64-1.80(\mathrm{~m}, 5 \mathrm{H}), 2.43$ (ddd, $J=3.5$, 5.5, 10.1 Hz, 1H), 2.81-2.89 (m, 1H), 3.22-3.29 (m, 2H), 7.25 $(\mathrm{d}, J=8.3 \mathrm{~Hz}, 2 \mathrm{H}), 7.75(\mathrm{~d}, J=8.3 \mathrm{~Hz}, 2 \mathrm{H}), 8.39$ (t, $J=6.0 \mathrm{~Hz}$, 1H), 8.64 (br s, $2 \mathrm{H}) ;{ }^{13} \mathrm{CNMR}\left(\mathrm{CD}_{3} \mathrm{OD}, 100 \mathrm{MHz}\right) \delta 14.3$, 22.4, 27.4, 27.6, 32.2, 34.3, 36.8, 37.9, 38.8, 127.4, 128.6, 134.3, 143.6, 169.6; HRMS (ESI) $m / z$ calcd. for $\mathrm{C}_{18} \mathrm{H}_{27} \mathrm{~N}_{2} \mathrm{O}$ $[\mathrm{M}+\mathrm{H}]^{+}$287.2118, found 287.2119.

4-(( \pm )-trans-2-aminocyclopropyl)- $N$-(4-fluorobenzyl)benzamide hydrochloride (5f). Yield $45 \%$, yellow solid; mp 98 ${ }^{\circ} \mathrm{C}$; IR 335, 2486, 1620, 1516, $1458 \mathrm{~cm}^{-1}$; ${ }^{1} \mathrm{H}$ NMR $\left(\mathrm{CD}_{3} \mathrm{OD}\right.$, $400 \mathrm{MHz}) \delta 1.37-1.42(\mathrm{~m}, 1 \mathrm{H}), 1.49$ (ddd, $J=4.7,7.0,10.2 \mathrm{~Hz}$, $1 \mathrm{H}), 2.43$ (ddd, $J=3.6,6.5,10.0 \mathrm{~Hz}, 1 \mathrm{H}), 2.89-2.96(\mathrm{~m}, 1 \mathrm{H})$, 4.53, (s, 2H), 7.0 (t, $J=8.7 \mathrm{~Hz}, 2 \mathrm{H}), 7.26(\mathrm{~d}, J=8.2,2 \mathrm{H}), 7.36$ (m, 2H), $7.81(\mathrm{~d}, J=8.3 \mathrm{~Hz}, 2 \mathrm{H}) ;{ }^{13} \mathrm{C}$ NMR $\left(\mathrm{CD}_{3} \mathrm{OD}, 100\right.$ $\mathrm{MHz}) \delta 14.3,22.4,32.3,43.8,116.2,127.5,128.5,130.4$, 133.9, 136.3, 143.9, 163.5 (d, $\left.J_{\mathrm{F}-\mathrm{C}}=220 \mathrm{~Hz}\right), 169.6$; HRMS (ESI) $\mathrm{m} / z$ calcd. for $\mathrm{C}_{17} \mathrm{H}_{18} \mathrm{~F}_{1} \mathrm{~N}_{2} \mathrm{O}[\mathrm{M}+\mathrm{H}]^{+} 285.1398$, found 285.1402 .

4-(( \pm )-trans-2-aminocyclopropyl)- $N$-(4-chlorobenzyl)benzamide hydrochloride (5g). Yield 15\%, yellow solid; mp 102 ${ }^{\circ} \mathrm{C}$ IR 3301, 2354, 1637, 1556, $1515 \mathrm{~cm}^{-1}$; ${ }^{1} \mathrm{HNMR}\left(\mathrm{CD}_{3} \mathrm{OD}\right.$, $400 \mathrm{MHz}) \delta 1.36-1.41(\mathrm{~m}, 1 \mathrm{H}), 1.48$ (ddd, $J=4.2,6.7,10.2 \mathrm{~Hz}$, $1 \mathrm{H}), 2.43$ (ddd, $J=3.1,6.2,9.9 \mathrm{~Hz}, 1 \mathrm{H}), 2.90-2.94(\mathrm{~m}, 1 \mathrm{H}), 4.5$ (s, 2H), 7.27 (d, J=8.3 Hz, 2H), 7.32 (s, 4H), 7.81 (d, $J=8.3 \mathrm{~Hz}$, $2 \mathrm{H}) ;{ }^{13} \mathrm{CNMR}\left(\mathrm{CD}_{3} \mathrm{OD}, 100 \mathrm{MHz}\right) \delta 14.7,22.8,32.4,43.9$, 123.4, 127.4, 128.8, 129.7, 130.2, 132.9, 139.0, 144.1, 172.1; HRMS (ESI) $m / z$ calcd. for $\mathrm{C}_{17} \mathrm{H}_{18} \mathrm{ClN}_{2} \mathrm{O}[\mathrm{M}+\mathrm{H}]^{+} 301.1102$, found 301.1102 .

4-(( \pm )-trans -2-aminocyclopropyl)- $\mathrm{N}$-(4-bromobenzyl)benzamide hydrochloride (5h). Yield $65 \%$, white solid; mp $97{ }^{\circ} \mathrm{C}$; IR 3320, 3035, 2665, 1637, 1533, $14893 \mathrm{~cm}^{-1}$; ${ }^{1} \mathrm{HNMR}\left(\mathrm{CD}_{3} \mathrm{OD}, 400 \mathrm{MHz}\right) \delta 1.37-1.42(\mathrm{~m}, 1 \mathrm{H}), 1.46-1.51$ (m, 1H), 2.44 (ddd, $J=3.2,6.3,9.7 \mathrm{~Hz}, 1 \mathrm{H}), 2.90-2.93(\mathrm{~m}, 1 \mathrm{H})$, 4.52 (s, 2H), 7.26 (d, $J=8.0 \mathrm{~Hz}, 4 \mathrm{H}), 7.47$ (d, $J=8.3 \mathrm{~Hz}, 2 \mathrm{H})$, $7.83(\mathrm{~d}, J=8.3 \mathrm{~Hz}, 2 \mathrm{H}) ;{ }^{13} \mathrm{CNMR}\left(\mathrm{CD}_{3} \mathrm{OD}, 100 \mathrm{MHz}\right) \delta 14.4$, 22.4, 32.3, 43.9, 121.8, 127.5, 128.8, 130.5, 132.6, 133.9, 139.6, 144.00, 169.7; HRMS (ESI) $\mathrm{m} / z$ calcd. for $\mathrm{C}_{17} \mathrm{H}_{18} \mathrm{BrN}_{2} \mathrm{O}[\mathrm{M}+\mathrm{H}]^{+}$345.0597, found 345.0602.
4-(( \pm -trans-2-aminocyclopropyl)- $N$-(4-methoxybenzyl)benzamide hydrochloride (5i). Yield 52\%, yellow solid; mp 123 ${ }^{\circ} \mathrm{C}$; IR 3364, 1672, $1528 \mathrm{~cm}^{-1}$; ${ }^{1} \mathrm{HNMR}\left(\mathrm{CD}_{3} \mathrm{OD}, 400 \mathrm{MHz}\right) \delta$ $1.36-1.41$ (m, 1H), 1.49 (ddd, $J=4.6,6.7,10.5 \mathrm{~Hz}, 1 \mathrm{H}), 2.44$ (ddd, $J=3.4,6.3,9.8 \mathrm{~Hz}, 1 \mathrm{H}), 2.91$, (ddd, $J=4.0,7.9,11.7 \mathrm{~Hz}$, $1 \mathrm{H}), 3.76(\mathrm{~s}, 3 \mathrm{H}), 4.48(\mathrm{~s}, 2 \mathrm{H}), 6.87(\mathrm{~d}, J=8.6 \mathrm{~Hz}, 2 \mathrm{H}), 7.25$ (d, $J=8.4 \mathrm{~Hz}, 2 \mathrm{H}), 7.26(\mathrm{~d}, J=8.4 \mathrm{~Hz}, 2 \mathrm{H}), 7.79(\mathrm{~d}, J=8.1 \mathrm{~Hz}, 2 \mathrm{H})$; ${ }^{13} \mathrm{CNMR}\left(\mathrm{CD}_{3} \mathrm{OD}, 100 \mathrm{MHz}\right) \delta 14.3,22.4,32.3,43.9,55.7$, 114.9, 127.5, 128.7, 129.8, 132.2, 134.1, 143.9, 160.4, 169.5; HRMS (ESI) $m / z$ calcd. for $\mathrm{C}_{18} \mathrm{H}_{21} \mathrm{~N}_{2} \mathrm{O}_{2}[\mathrm{M}+\mathrm{H}]^{+}$297.1598, found 297.1595 .

$N$-([1,1'-biphenyl]-4-ylmethyl)-4- ( \pm trans -2 -aminocyclopropyl) benzamide hydrochloride (5j). Yield 34\% yellow solid; IR 3402, 3045, 1715, 1632, $1540 \mathrm{~cm}^{-1}$; ${ }^{\mathrm{H}} \mathrm{NMR}$ $\left(\mathrm{CD}_{3} \mathrm{OD}, 400 \mathrm{MHz}\right) \delta 1.38-1.43(\mathrm{~m}, 1 \mathrm{H}), 1.46-1.50(\mathrm{~m}, 1 \mathrm{H})$, 2.43 (ddd, $J=3.5,6.3,10.2 \mathrm{~Hz}, 1 \mathrm{H}), 2.92$ (ddd, $J=3.7,7.9$, $11.6 \mathrm{~Hz}, 1 \mathrm{H}), 4.61(\mathrm{~s}, 2 \mathrm{H}), 7.26-7.29(\mathrm{~m}, 2 \mathrm{H}), 7.30-7.34(\mathrm{~m}$, $1 \mathrm{H}), 7.39-7.45(\mathrm{~m}, 4 \mathrm{H}), 7.56-7.60(\mathrm{~m}, 4 \mathrm{H}), 7.83(\mathrm{~d}, J=8.4 \mathrm{~Hz}$, $2 \mathrm{H}) ;{ }^{13} \mathrm{C}$ NMR $\left(\mathrm{CD}_{3} \mathrm{OD}, 100 \mathrm{MHz}\right) \delta 14.3,22.4,32.2,44.1$, $127.4,127.8,128.0,128.2,128.7,128.9,129.7,134.0,139.2$, $141.3,142.0,143.8,169.6$.

4-( \pm -trans-2-aminocyclopropyl)- $\mathrm{N}$-(2-amino-2-oxoethyl)- benzamide hydrochloride (5k). Yield 15\%, yellow oil; ${ }^{1} \mathrm{H}$ NMR $\left(\mathrm{CD}_{3} \mathrm{OD}, 400 \mathrm{MHz}\right) \delta 1.38-1.42$ (m, 1H), 1.47$1.52(\mathrm{~m}, 1 \mathrm{H}), 2.43-2.48(\mathrm{~m}, 1 \mathrm{H}), 2.91-2.94(\mathrm{~m}, 1 \mathrm{H}), 3.74(\mathrm{~s}$, $1 \mathrm{H}), 4.02(\mathrm{~s}, 1 \mathrm{H}), 4.08,(\mathrm{~s}, 1 \mathrm{H}), 7.31(\mathrm{dd}, J=2.7,8.0 \mathrm{~Hz}, 2 \mathrm{H})$, $7.85(\mathrm{t}, J=7.60 \mathrm{~Hz}, 2 \mathrm{H}) ;{ }^{13} \mathrm{C} \mathrm{NMR}\left(\mathrm{CD}_{3} \mathrm{OD}, 100 \mathrm{MHz}\right) \delta 14.6$, 22.3, 32.3, 42.3, 127.5, 128.9, 133.5, 144.3, 169.2, 172.8; HRMS (ESI) $m / z$ calcd. $\mathrm{C}_{12} \mathrm{H}_{16} \mathrm{~N}_{3} \mathrm{O}_{2}[\mathrm{M}+\mathrm{H}]^{+} 234.1237$, found 234.12068 .

4-( \pm -trans-2-aminocyclopropyl)- $\mathbf{N}, \boldsymbol{N}$-dibenzylbenzamide hydrochloride (5l). Yield 52\%, yellow solid; IR 3214, 1645.7, $1620,1452 \mathrm{~cm}^{-1}$; ${ }^{1} \mathrm{HNMR}\left(\mathrm{CD}_{3} \mathrm{OD}, 400 \mathrm{MHz}\right) \delta 1.37-1.38(\mathrm{~m}$, $1 \mathrm{H}), 1.49-1.56(\mathrm{~m}, 1 \mathrm{H}), 2.43$ (ddd, $J=3.2,6.4,9.8 \mathrm{~Hz}, 1 \mathrm{H})$, 2.96-2.90 (m, 1H), 4.43 (br s, 2H), 4.66 (br s, 2H), 7.12 (br s, 2H), 7.24-7.30 (m, 7H), 7.32-7.39 (m, 5H), 7.43-7.50 (m, 2H); ${ }^{13} \mathrm{CNMR}\left(\mathrm{CD}_{3} \mathrm{OD}, 100 \mathrm{MHz}\right) \delta 14.1,22.3,32.3,53.7,127.6$, 128.0, 128.2, 128.7, 129.8, 129.9, 135.5, 142.2, 174.2; HRMS (ESI) $\mathrm{m} / z$ calcd. for $\mathrm{C}_{24} \mathrm{H}_{25} \mathrm{~N}_{2} \mathrm{O}_{1}[\mathrm{M}+\mathrm{H}]^{+}, 357.1961$, found 357.1960 .

4-(( \pm -trans-2-aminocyclopropyl) phenyl)4-(2-fluorophenyl)piperazin-1-yl)methanone hydrochloride (5m).Yield 44\%, yellow solid; IR 3387, 1603, 1505, $1470 \mathrm{~cm}^{-}$ ', ${ }^{1} \mathrm{H}$ NMR $\left(\mathrm{CD}_{3} \mathrm{OD}, 400 \mathrm{MHz}\right) \delta 1.37-1.42(\mathrm{~m}, 1 \mathrm{H}), 1.44$ $1.49(\mathrm{~m}, 1 \mathrm{H}), 2.42$ (ddd, $J=3.2,6.3,9.7 \mathrm{~Hz}, 1 \mathrm{H}), 2.89-2.93$ (m, 1H), 3.16 (br s, 4H), 3.66 (br s 2H), 3.94 (br s 2H), 7.037.13 (m, 4H), 7.28 (d, J=7.6 Hz, 2H), 7.42 (d, J=7.8 Hz, 2H); ${ }^{13} \mathrm{C}$ NMR $\left(\mathrm{CD}_{3} \mathrm{OD}, 100 \mathrm{MHz}\right) \delta 14.5,22.4,32.4,54.9,68.0$, $117.7,122.3,126.6,127.9,128.4,128.9,134.3,135.9,142.6$, $156.6\left(\mathrm{~d}, J_{\mathrm{F}-\mathrm{C}=} 245.8 \mathrm{~Hz}\right), 172.19$; HRMS (ESI) $\mathrm{m} / \mathrm{z}$ calcd. for $\mathrm{C}_{20} \mathrm{H}_{23} \mathrm{~F}_{1} \mathrm{~N}_{3} \mathrm{O}[\mathrm{M}+\mathrm{H}]^{+}$340.1820, found 340.1821 .

2-(4-(4-( \pm -trans-2-aminocyclopropyl)benzoyl)piperazin1-yl)benzonitrile hydrochloride (5n). Yield 39\%, white solid; IR 3353, 2856, 2221, 1632, $1562 \mathrm{~cm}^{-1}$; ${ }^{1} \mathrm{H}$ NMR $\left(\mathrm{CD}_{3} \mathrm{OD}, 400 \mathrm{MHz}\right) \delta 1.38-1.42(\mathrm{~m}, 1 \mathrm{H}), 1.44-1.51(\mathrm{~m}, 1 \mathrm{H})$, 2.40-2.45 (m, 1H), 2.92 (ddd, $J=4.2,8.0,11.0 \mathrm{~Hz}, 1 \mathrm{H}), 3.18$ (br s, 2H), 3.56-3.59 (m, 1H), 3.64-3.68 (m, 3H), 3.71-3.74 (m, 2H), 3.95 (br s, 1H), 7.14 (t, $J=7.4 \mathrm{~Hz}, 1 \mathrm{H}), 7.19$ (d, $J=8.2$ $\mathrm{Hz}, 1 \mathrm{H}), 7.29$ (d, $J=8.0 \mathrm{~Hz}, 2 \mathrm{H}), 7.43$ (d, $J=8.0 \mathrm{~Hz}, 2 \mathrm{H}), 7.57-$ $7.61(\mathrm{~m}, 1 \mathrm{H}), 7.65(\mathrm{dd}, J=2.07,9.06 \mathrm{~Hz}, 1 \mathrm{H}) ;{ }^{13} \mathrm{C} \mathrm{NMR}$ $\left(\mathrm{CD}_{3} \mathrm{OD}, 100 \mathrm{MHz}\right) \delta 14.2,22.4,32.2,43.7,62.2,107.7$, $119.1,120.6,124.0,127.7,128.7,135.1,135.3,135.4,142.3$, 
156.6, 172.3; HRMS (ESI) $m / z$ calcd. for $\mathrm{C}_{21} \mathrm{H}_{23} \mathrm{~N}_{4} \mathrm{O}[\mathrm{M}+\mathrm{H}]^{+}$, 347.1866 , found 347.1869 .

4-(( \pm -trans -2-aminocyclopropyl)phenyl)4-(pyridin-2yl)piperazin-1-yl)methanone hydrochloride (5o). Yield $13 \%$, orange oil; IR 3358, 1603, 1545, $1435 \mathrm{~cm}^{-1}$; ${ }^{1} \mathrm{HNMR}$ $\left(\mathrm{CD}_{3} \mathrm{OD}, 400 \mathrm{MHz}\right) \delta 1.37-1.43(\mathrm{~m}, 1 \mathrm{H}), 1.51(\mathrm{ddd}, J=4.4$, 6.6, $11.1 \mathrm{~Hz}, 1 \mathrm{H}$ ), 2.48 (ddd, $J=3.5,6.3,10.0 \mathrm{~Hz}, 1 \mathrm{H}$ ), 2.93 (ddd, $J=4.4,7.6,11.2 \mathrm{~Hz}, 1 \mathrm{H}), 3.8$ (br s, 8H), 7.06 (t, $J=6.5$ $\mathrm{Hz}, 1 \mathrm{H}), 7.32$ (d, $J=8.0 \mathrm{~Hz}, 2 \mathrm{H}), 7.42$ (d, $J=9.2 \mathrm{~Hz}, 1 \mathrm{H}), 7.48$ $(\mathrm{d}, J=8.0 \mathrm{~Hz}, 2 \mathrm{H}), 8.0(\mathrm{dd}, J=1.24,7.9 \mathrm{~Hz}, 1 \mathrm{H}), 8.05$ (dt, $J=1.6,8.5 \mathrm{~Hz}, 1 \mathrm{H}) ;{ }^{13} \mathrm{CNMR}\left(\mathrm{CD}_{3} \mathrm{OD}, 100 \mathrm{MHz}\right) \delta 14.3$, 22.4, 32.2, 44.8, 47.2, 114.3, 127.8, 128.8, 131.1, 134.5, 137.5, 142.8, 145.7, 153.7, 172.6; HRMS (ESI) $\mathrm{m} / \mathrm{z}$ calcd. for $\mathrm{C}_{19} \mathrm{H}_{23} \mathrm{~N}_{4} \mathrm{O}[\mathrm{M}+\mathrm{H}]^{+}$323.1866, found 323.1869.

4-(土)-trans-2-aminocyclopropyl-phenyl)-(4-(pyrimidin-2yl)piperazin-1-yl)methanone hydrochloride (5p). Yield 22 $\%$, red oil; IR 3353,1678, 1632, $1551 \mathrm{~cm}^{-1}$; ${ }^{1} \mathrm{H}$ NMR $\left(\mathrm{CD}_{3} \mathrm{OD}\right.$, $400 \mathrm{MHz}) \delta 1.39-1.45(\mathrm{~m}, 1 \mathrm{H}), 1.47$ (ddd, $J=4.5,6.9,10.1 \mathrm{~Hz}$, $1 \mathrm{H}), 2.44$ (ddd, $J=3.6,6.4,10.2 \mathrm{~Hz}, 1 \mathrm{H}), 2.92-2.96(\mathrm{~m}, 1 \mathrm{H})$, 3.53 (br s, 2H), 3.82 (br s, 4H), 3.94 (br s, 2H), 6.66 (t, $J=4.7$, $\mathrm{Hz}, 1 \mathrm{H}), 7.29$ (d, $J=8.2 \mathrm{~Hz}, 2 \mathrm{H}), 7.42$ (d, $J=8.3 \mathrm{~Hz}, 2 \mathrm{H}), 8.35$ $(\mathrm{d}, J=4.8 \mathrm{~Hz}, 2 \mathrm{H}) ;{ }^{13} \mathrm{C}$ NMR $\left(\mathrm{CD}_{3} \mathrm{OD}, 100 \mathrm{MHz}\right) \delta 14.2,22.4$, 32.1, 40.4, 41.7, 111.8, 127.7, 128.6, 135.2, 142.3, 159.1, 162.8, 172.45; HRMS (ESI) $\mathrm{m} / z$ calcd. for $\mathrm{C}_{18} \mathrm{H}_{22} \mathrm{~N}_{5} \mathrm{O}$ $[\mathrm{M}+\mathrm{H}]^{+} 324.1819$, found 324.1824 .

4-(( \pm$)$-trans-2-aminocyclopropyl)phenyl)(4(phenylsulfonyl) piperazin-1-yl)methanone hydrochloride (5q). Yield 25\%, white solid; IR 3392, 1637, 1652, $1551 \mathrm{~cm}^{-1}$; ${ }^{1} \mathrm{H}$ NMR $\left(\mathrm{CD}_{3} \mathrm{OD}, 400 \mathrm{MHz}\right) \delta 1.33-1.38(\mathrm{~m}, 1 \mathrm{H}), 1.45-1.50$ (m, 1H), 2.41-2.43 (m, 1H), $2.45(\mathrm{~s}, 3 \mathrm{H}), 2.87-2.89(\mathrm{~m}, 1 \mathrm{H})$, 3.00 (br s, 4H), 3.56 (br s, 2H), 3.77 (br s, 2H), 7.22 (d, $J=7.6$ $\mathrm{Hz}, 2 \mathrm{H}), 7.30,(\mathrm{~d}, J=7.6 \mathrm{~Hz}, 2 \mathrm{H}), 7.44$ (d, $J=7.8 \mathrm{~Hz}, 2 \mathrm{H}), 7.65$ $(\mathrm{d}, J=7.9 \mathrm{~Hz}, 2 \mathrm{H}) ;{ }^{13} \mathrm{C} \mathrm{NMR}\left(\mathrm{CD}_{3} \mathrm{OD}, 200 \mathrm{MHz}\right) \delta 14.2,21.5$, 22.3, 32.2, 44.2, 47.2, 127.7, 128.6, 128.9, 130.9, 133.8,

$134.5,142.4,145.6,172.2$; HRMS (ESI) $\mathrm{m} / z$ calcd. for $\mathrm{C}_{21} \mathrm{H}_{26} \mathrm{~N}_{3} \mathrm{O}_{3} \mathrm{~S}[\mathrm{M}+\mathrm{H}]^{+} 400.1689$, found 400.1687 .

4-( \pm -trans-2-aminocyclopropyl)phenyl(4-(methylsulfonyl)piperazin-1-yl)methanone hydrochloride (5r). Yield 37\%, white solid; IR 3387, 1614, $1562 \mathrm{~cm}^{-1} ;{ }^{1} \mathrm{HNMR}$ $\left(\mathrm{CD}_{3} \mathrm{OD}, 400 \mathrm{MHz}\right) \delta 1.37-1.42(\mathrm{~m}, 1 \mathrm{H}), 1.47$ (ddd, $J=4.5,6.8$, $10.3 \mathrm{~Hz}, 1 \mathrm{H}), 2.42$ (ddd, $J=3.6,6.6,10.2 \mathrm{~Hz}, 1 \mathrm{H}), 2.87$ (s, 3H), 2.89-2.93 (m, 1H), 3.26 (br s, 4H), 3.57 (br s, 2H), 3.8, (br s, 2H), 7.28 (d, $J=8.2 \mathrm{~Hz}, 2 \mathrm{H}), 7.41$ (d, $J=8.3 \mathrm{~Hz}, 2 \mathrm{H}) ;{ }^{13} \mathrm{CNMR}$ $\left(\mathrm{CD}_{3} \mathrm{OD}, 100 \mathrm{MHz}\right) \delta 14.2,22.4,32.0,34.8,46.7,68.0,127.8$, 128.6, 134.7, 142.4, 172.3; HRMS (ESI) $\mathrm{m} / \mathrm{z}$ calcd for $\mathrm{C}_{15} \mathrm{H}_{24} \mathrm{~N}_{3} \mathrm{O}_{3} \mathrm{~S}[\mathrm{M}+\mathrm{H}]+324.1380$, found 324.1380 .
FIGURES (Word Style "VA_Figure_Caption"). Each figure must have a caption that includes the figure number and a brief description, preferably one or two sentences. The caption should follow the format "Figure 1. Figure caption." All figures must be mentioned in the text consecutively and numbered with Arabic numerals. The caption should be understandable without reference to the text. Whenever possible, place the key to symbols in the artwork, not in the caption. To insert the figure into the template, be sure it is already sized appropriately and paste before the figure caption. For formatting double-column figures, see the instructions at the end of the template. Do NOT modify the amount of space before and after the caption as this allows for the rules, space above and below the rules, and space above and below the figure to be inserted upon editing.

SCHEMES (Word Style "VC_Scheme_Title"). Groups of reactions that show action are called schemes. Schemes may have brief titles describing their contents. The title should follow the format "Scheme 1. Scheme Title". Schemes may also have footnotes (use Word Style "FD_Scheme_Footnote"). To insert the scheme into the template, be sure it is already sized appropriately and paste after the scheme title. For formatting double-column schemes, see the instructions at the end of the template. Do NOT modify the amount of space before and after the title as this allows for the rules, space above and below the rules, and space above and below the scheme to be inserted upon editing.

CHARTS (Word Style "VB_Chart_Title"). Groups of structures that do not show action are called charts. Charts may have brief titles describing their contents. The title should follow the format "Chart 1. Chart Title". Charts may also have footnotes (use Word Style "FC_Chart_Footnote"). To insert the chart into the template, be sure it is already sized appropriately and paste after the chart title. For formatting double-column charts, see the instructions at the end of the template. Do NOT modify the amount of space before and after the title as this allows for the rules, space above and below the rules, and space above and below the chart to be inserted upon editing.

TABLES. Each table must have a brief (one phrase or sentence) title that describes its contents. The title should follow the format "Table 1. Table Title" (Word Style "VD_Table_Title"). The title should be understandable without reference to the text. Put details in footnotes, not in the title (use Word Style "FE_Table_Footnote"). Do NOT modify the amount of space before and after the title as this allows for the space above and below the table to be inserted upon editing.

Use tables (Word Style "TC_Table_Body") when the data cannot be presented clearly as narrative, when many precise numbers must be presented, or when more meaningful interrelationships

can be conveyed by the tabular format. Do not use Word Style “TC_Table_Body" for tables containing artwork. Tables should supplement, not duplicate, text and figures. Tables should be simple and concise. It is preferable to use the Table Tool in your word-processing package, placing one entry per cell, to generate tables.

Displayed equations can be inserted where desired making sure they are assigned Word Style "Normal". Displayed equations can only be one column wide. If the artwork needs to be two columns wide, it must be relabeled as a figure, chart, or scheme and mentioned as such in the text. 


\section{ASSOCIATED CONTENT}

\section{Supporting Information}

(Word Style "TE_Supporting_Information"). (Word Style "TE_Supporting_Information"). A listing of the contents of each file supplied as Supporting Information should be included. For instructions on what should be included in the Supporting Information as well as how to prepare this material for publication, refer to the journal's Instructions for Authors.

The Supporting Information is available free of charge on the ACS Publications website.

brief description (file type, i.e., PDF)

brief description (file type, i.e., PDF)

\section{AUTHOR INFORMATION}

\section{Corresponding Author}

* (Word Style "FA_Corresponding_Author_Footnote"). Give contact information for the author(s) to whom correspondence should be addressed.

\section{Present Addresses}

$\dagger$ If an author's address is different than the one given in the affiliation line, this information may be included here.

\section{Author Contributions}

The manuscript was written through contributions of all authors. / All authors have given approval to the final version of the manuscript. / †These authors contributed equally. (match statement to author names with a symbol)

\section{Funding Sources}

Any funds used to support the research of the manuscript should be placed here (per journal style).

Notes

Any additional relevant notes should be placed here.

\section{ACKNOWLEDGMENT}

(Word Style "TD_Acknowledgments"). Generally the last paragraph of the paper is the place to acknowledge people (dedications), places, and financing (you may state grant numbers and sponsors here). Follow the journal's guidelines on what to include in the Acknowledgement section.

\section{ABBREVIATIONS}

CCR2, CC chemokine receptor 2; CCL2, CC chemokine ligand 2; CCR5, CC chemokine receptor 5; TLC, thin layer chromatography.

\section{REFERENCES}

(Word Style "TF_References_Section"). References are placed at the end of the manuscript. Authors are responsible for the accuracy and completeness of all references. Examples of the recommended formats for the various reference types can be found at http://pubs.acs.org/page/4authors/index.html. Detailed information on reference style can be found in The ACS Style Guide, available from Oxford Press. 
Figure 1. Mechanism of action of tranylcypromine.

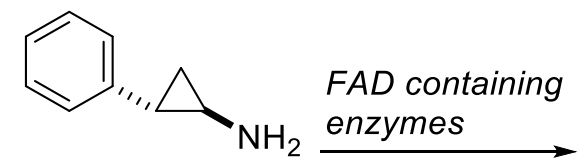

(士)-tranylcypromine 1<smiles>[NH3+][C@@H]1C[C@H]1c1ccccc1</smiles>

2 strain induced ring opening<smiles>Cc1cccc(CCC=[NH2+])c1</smiles>

Figure 2. Carboxamide containing tranylcypromine analogues.<smiles>[R]C(=O)Nc1ccc([C@H]2C[C@H]2N)cc1</smiles>

Mai, Takeda series 4<smiles>[R2]N([R2])C(=O)c1ccc(C2CC2N)cc1</smiles>

this work

5

Scheme 1. Synthesis of novel KDM1A inhibitors<smiles>COC(=O)c1ccc(C=CC(=O)OCC(C)(C)C(C)(C)C)cc1</smiles><smiles>COC(=O)c1ccc([C@]2(c3ccc(C(=O)OCc4ccccc4)cc3)C[C@H]2NC(=O)OCc2ccccc2)cc1</smiles><smiles>[3H][3H]</smiles>

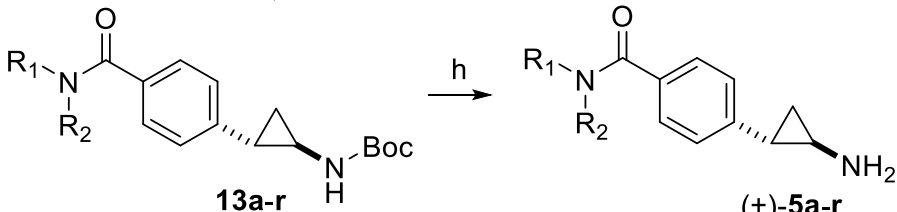

Reagents and conditions: (a) $\mathrm{AcCl}, \mathrm{MeOH}, 0{ }^{\circ} \mathrm{C}$ to rt, overnight, 91\%; (b) $t$-Butyl diethylphosphonoacetate, $\mathrm{KO} t$-Bu, THF, $5{ }^{\circ} \mathrm{C}$ to rt, overnight, $98 \%$; (c) $\mathrm{Me}_{3} \mathrm{~S}(\mathrm{O})^{+} \mathrm{I}^{-}, \mathrm{NaH}$, DMSO, rt, overnight, 23\%; (d) TFA, $\mathrm{Et}_{3} \mathrm{SiH}_{2} \mathrm{CH}_{2} \mathrm{Cl}_{2}, \mathrm{rt}, \mathrm{overnight}, 72 \%$; 
(e) Diphenylphosphoryl azide, Et $3 \mathrm{~N}, t$-BuOH, reflux, $72 \mathrm{~h}, 42 \%$; (f) $\mathrm{LiOH}$, aq THF, $50{ }^{\circ} \mathrm{C}, 2 \mathrm{~h}, 82 \%$; (g) $\mathrm{R}_{1} \mathrm{R}_{2} \mathrm{NH}, \mathrm{EDCI}$, HOBt, Hünig's base, rt, overnight, 36-67\%; (h) HCl, THF, 13-71\%.

Table 1. LSD1 enzyme inhibition assay with compounds 5a-r with tranylcypromine 1 as a reference.

\begin{tabular}{|c|c|c|}
\hline Compound & $\mathrm{R}_{1} \mathrm{R}_{2} \mathrm{~N}$ & $\mathrm{IC}_{50}(\mu \mathrm{M} \pm \mathrm{SEM}, \mathrm{n}=3)$ \\
\hline 1 & & 21 \\
\hline $5 \mathrm{a}$ & & $0.3 \pm 0.008$ \\
\hline $5 b$ & & $0.4 \pm 0.004$ \\
\hline $5 c$ & & $0.6 \pm 0.08$ \\
\hline $5 d$ & & $2.4 \pm 0.99$ \\
\hline $5 e$ & & $5.8 \pm 0.47$ \\
\hline $5 f$ & & $1.3 \pm 0.26$ \\
\hline $5 \mathrm{~g}$ & & $>50$ \\
\hline $5 \mathrm{~h}$ & & $0.9 \pm 0.18$ \\
\hline $5 \mathrm{i}$ & & $32 \pm 0.25$ \\
\hline $5 \mathrm{j}$ & & $17.4 \pm 3.9$ \\
\hline
\end{tabular}




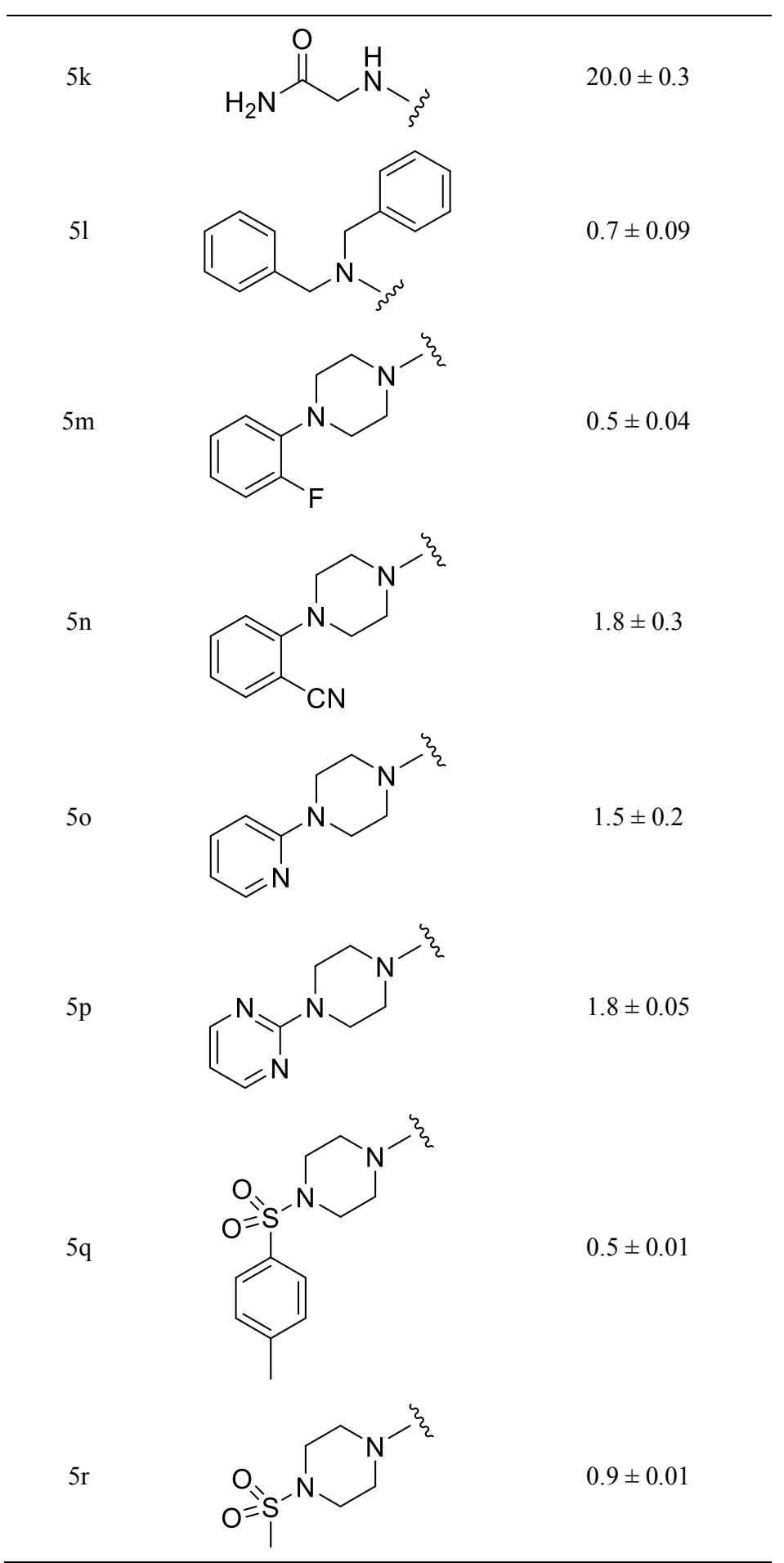


Table 2. : In vitro anti-proliferative results of selected tranylcypromine analogues in AML cell lines, with tranylcypromine as a standard. Values are reported in $\mu \mathrm{M} \pm \mathrm{SEM}(\mathrm{n}=5), \mathrm{nt}=$ not tested.

$$
\mathrm{IC}_{50}(\mu \mathrm{M} \pm \mathrm{SEM}, \mathrm{n}=5)
$$

\begin{tabular}{ccccccc}
\hline Compound & & & & & & \\
& KASUMI-1 & U937 & HL-60 & OCI-AML3 & THP-1 & MV4-11 \\
\hline $\mathbf{1}$ & $32 \pm 1.8$ & $>100$ & $84 \pm 15.0$ & $89 \pm 13.0$ & $81 \pm 3.9$ & $63 \pm 8.4$ \\
$\mathbf{5 a}$ & $0.03 \pm 1.3$ & $1.6 \pm 42.3$ & $1.7 \pm 14.5$ & $1.8 \pm 7.6$ & $0.1 \pm 17.5$ & $0.18 \pm 7.2$ \\
$\mathbf{5 b}$ & $0.7 \pm 0.3$ & $1.2 \pm 2.1$ & $0.09 \pm 0.7$ & $0.06 \pm 4.2$ & $0.2 \pm 2.1$ & $0.19 \pm 3.6$ \\
$\mathbf{5 c}$ & $0.4 \pm 8.2$ & $0.6 \pm 0.1$ & $0.6 \pm 0.1$ & $\mathrm{nt}$ & $1.0 \pm 0.1$ & $0.1 \pm 0.8$ \\
$\mathbf{5 d}$ & $0.4 \pm 2.7$ & $0.6 \pm 0.8$ & $\mathrm{nt}$ & $\mathrm{nt}$ & $\mathrm{nt}$ & $1.2 \pm 4.7$ \\
$\mathbf{5 e}$ & $0.3 \pm 2.7$ & $\mathrm{nt}$ & $\mathrm{nt}$ & $\mathrm{nt}$ & $\mathrm{nt}$ & $0.1 \pm 0.2$ \\
$\mathbf{5 f}$ & $0.06 \pm 0.8$ & $\mathrm{nt}$ & $\mathrm{nt}$ & $\mathrm{nt}$ & $0.4 \pm 0.1$ & $0.2 \pm 7.3$ \\
$\mathbf{5 h}$ & $0.02 \pm 0.1$ & $\mathrm{nt}$ & $\mathrm{nt}$ & $\mathrm{nt}$ & $\mathrm{nt}$ & $0.2 \pm 2.3$ \\
$\mathbf{5 m}$ & $\mathrm{nt}$ & $\mathrm{nt}$ & $0.1 \pm 0.02$ & $0.2 \pm 0.01$ & $\mathrm{nt}$ & $\mathrm{nt}$ \\
$\mathbf{5 n}$ & $\mathrm{nt}$ & $\mathrm{nt}$ & $0.3 \pm 0.01$ & $\mathrm{nt}$ & $\mathrm{nt}$ & $\mathrm{nt}$ \\
$\mathbf{5 p}$ & $2.3 \pm 1.4$ & $\mathrm{nt}$ & $0.6 \pm 0.3$ & $\mathrm{nt}$ & $\mathrm{nt}$ & $\mathrm{nt}$ \\
$\mathbf{5 r}$ & $\mathrm{nt}$ & $\mathrm{nt}$ & $\mathrm{nt}$ & $\mathrm{nt}$ & $\mathrm{nt}$ & $0.2 \pm 0.7$
\end{tabular}


Figure 3. Washout experiments with TCP derivatives 5a-c. Cells were treated with $200 \mathrm{nM}$ of compound $7 \mathrm{a}-\mathrm{c}$ respectively for $72 \mathrm{~h}$ continuously or intermittently ( $6 \mathrm{~h}$ and then washout). Survival rates were measured with CellTiter-Glo ${ }^{\circledR}$ and RLU was normalised to control (Vehicle-DMSO). Statistical significance was determined with two-way ANOVA and corrected for multiple comparisons using Bonferoni's test. Data are shown as means \pm SEM $(n=5)$. Results showed no significant differences in survival rates between the two populations. (A) Schematic of representative workflow for wash out experiment. (B) Washout results.

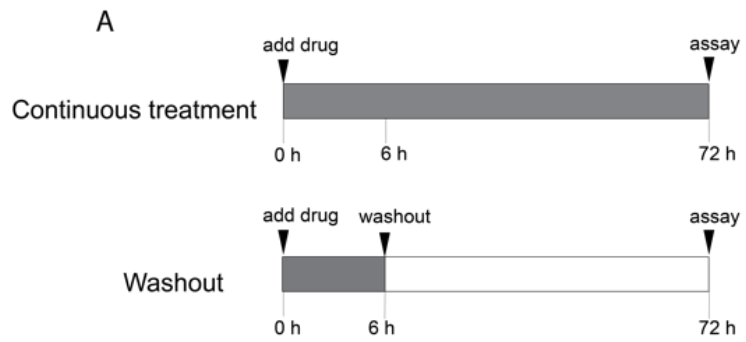

B
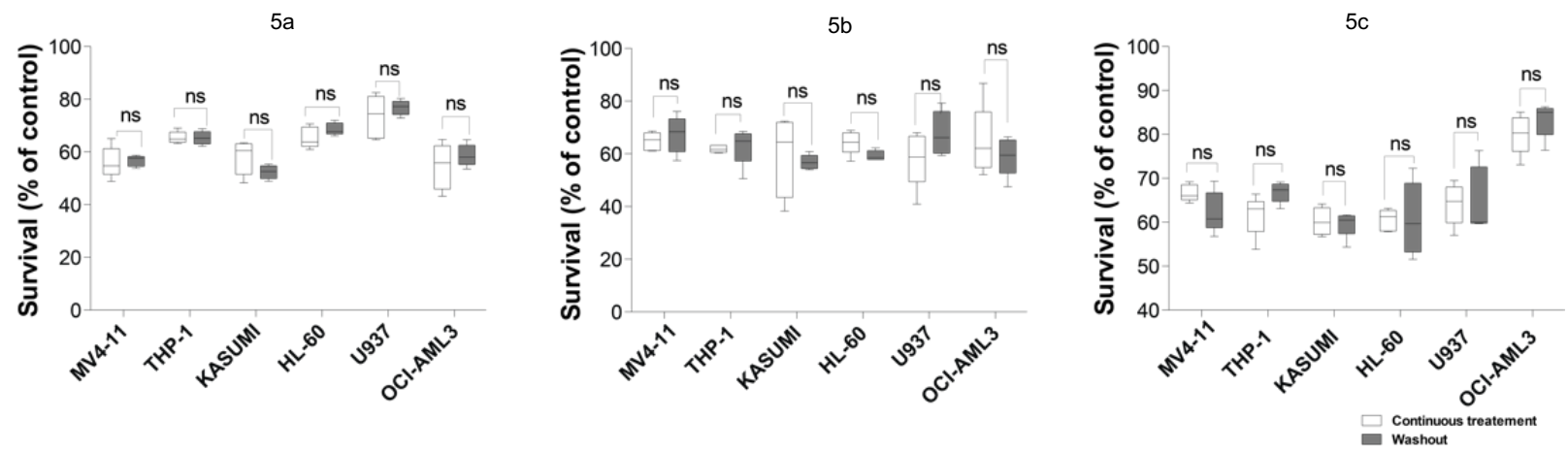

Figure 4. Effects of $5 \mathrm{~b}$ on the expression of $\mathrm{H} 3 \mathrm{~K} 4 \mathrm{me} 2$ and $\mathrm{H} 3$ (total, loading control) in KASUMI-1 cells (200 nM) after 2, 4, 6, 48 and 72 h.

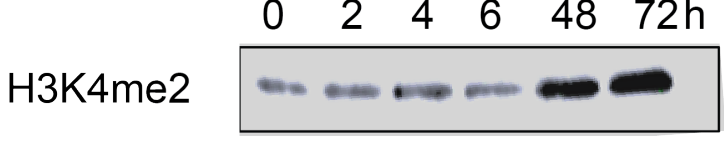

H3 (total)

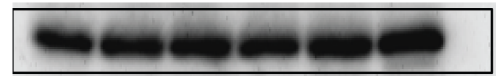


Figure 5. Effects on the expression of CD86 in THP1 cells after treatment with $5 \mathrm{~b}$ (200 nM, 72 h). From Top to bottom DMSO control cells sample stained with IgG1-FITC (isotype control) (plots A-C) or stained with CD86-FITC antibody (D-F); THP-1 treated with $200 \mathrm{nM}$ of $5 \mathrm{~b}(72 \mathrm{~h})$ stained with IgG1-FITC (isotype control) plots G-I or CD86-FITC antibody (J-L). Forward scatter (FSC)/side scatter (SSC) used to gate the population of interest (R1) plots (A, D, G, J). In the X-axis are reported the mean fluorescence intensities of treated cells stained with FITC conjugated Ab and the fluorescent increase of control (untreated cells-IgG IsotypeFITC). The $\mathrm{Y}$-axis is the cell count 

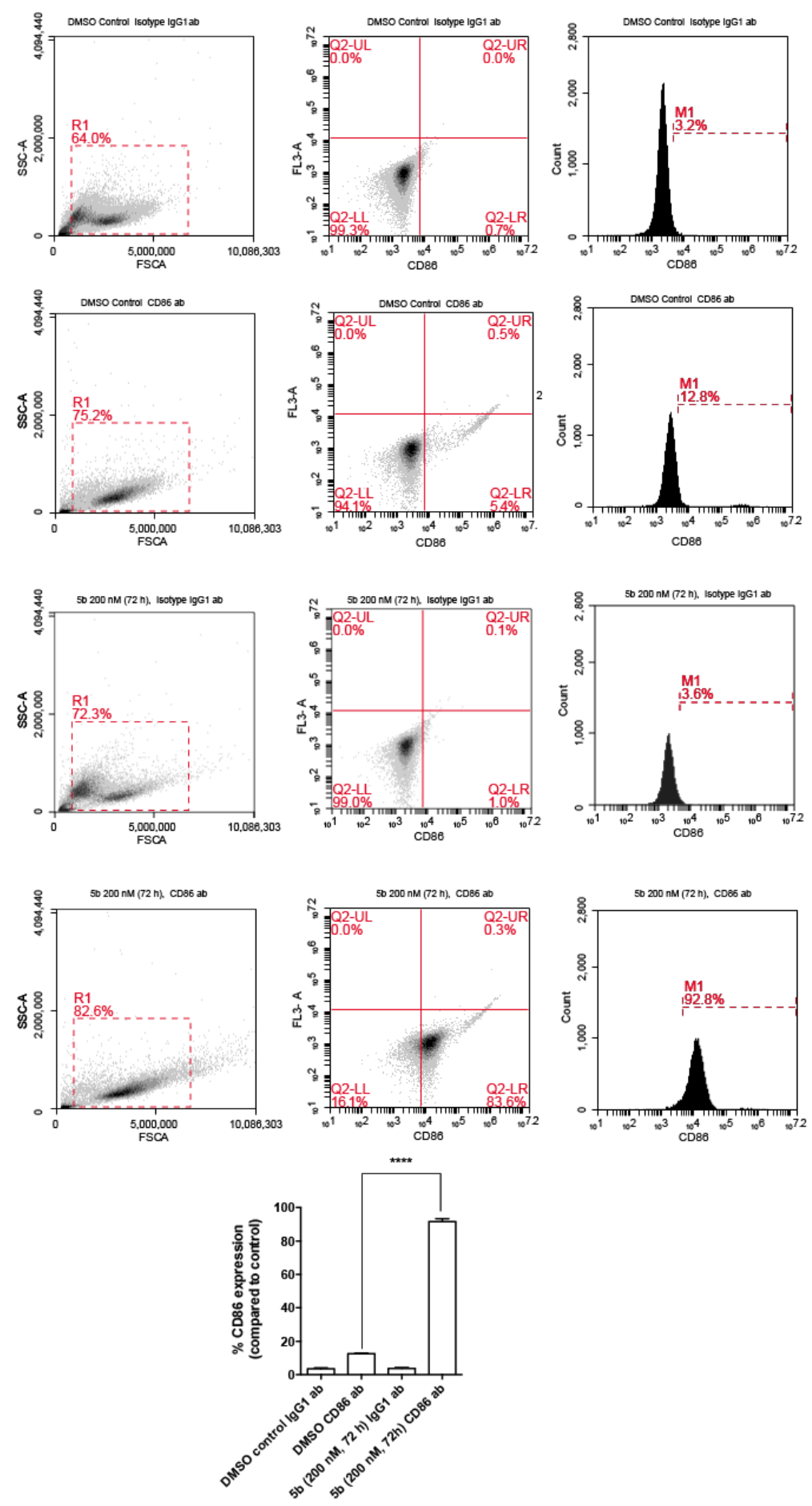

Table 3. Increase (\%) of CD86 expression induced by 5a-c in AML cell lines (200 nM, 72 h).

\begin{tabular}{ccc} 
Compound $(200 \mathrm{nM})$ & Cell line & $72 \mathrm{~h}$ \\
\hline $5 \mathrm{a}$ & & $92.9 \pm 1.2 \%$ \\
$5 \mathrm{~b}$ & THP-1 & $92.4 \pm 3.3 \%$ \\
$5 \mathrm{c}$ & & $40.3 \pm 1.9 \%$ \\
\hline
\end{tabular}




\begin{tabular}{ccc}
\hline $5 \mathrm{a}$ & & $79.5 \pm 3.2 \%$ \\
$5 \mathrm{~b}$ & MV4-11 & $81.2 \pm 2.5 \%$ \\
& & $94.1 \pm 0.3 \%$ \\
\hline $\mathrm{c}$ & & $65.5 \pm 4.3 \%$ \\
$5 \mathrm{a}$ & OCI-AML3 & $69.8 \pm 5.7 \%$ \\
$5 \mathrm{~b}$ & & $78.3 \pm 3.7 \%$ \\
\hline $\mathrm{c}$ & & $81.7 \pm 3.1 \%$ \\
\hline $5 \mathrm{a}$ & KASUMI-1 & $73.8 \pm 3.4 \%$ \\
$5 \mathrm{~b}$ & & $69.0 \pm 1.7 \%$ \\
\hline $\mathrm{c}$ & &
\end{tabular}


Figure 6. Effects of 5a (200 $\mathrm{nM}, 48 \mathrm{~h})$ on the expression of CD14 and CD11b in MV4-11.

FSC and SSC profiles were applied for the initial gating by selecting cell size and distribution and remove cell debris. Plots A, B, C show the Isotype controls. Plots D, E, F show the experimental conditions. Plots A and D show the gated population: in the X-axis is reported the mean fluorescence intensities for FITC-CD14 Ab; in the Y-axis is reported the mean fluorescence increase for PE-CD11b Ab. Plots B and $\mathrm{C}$ (black histograms) report the fluorescence increase of Isotype controls (untreated cells); E shows the fluorescence increase of the monocytic marker CD14; F shows the fluorescence increase of the myeloid marker CD11b. Numbers shown in each box are the \% of cells expressing CD14 or CD11b. (G) Shown are results graphically summarised for three independent experiments. Statistical significance was determined with two-way ANOVA and corrected for multiple comparisons with Bonferroni's test. Values are expressed as means \% of CD14-CD11b increase $\pm \operatorname{STD}(\mathrm{n}=3) ; * * * \mathrm{p}<0.001$.
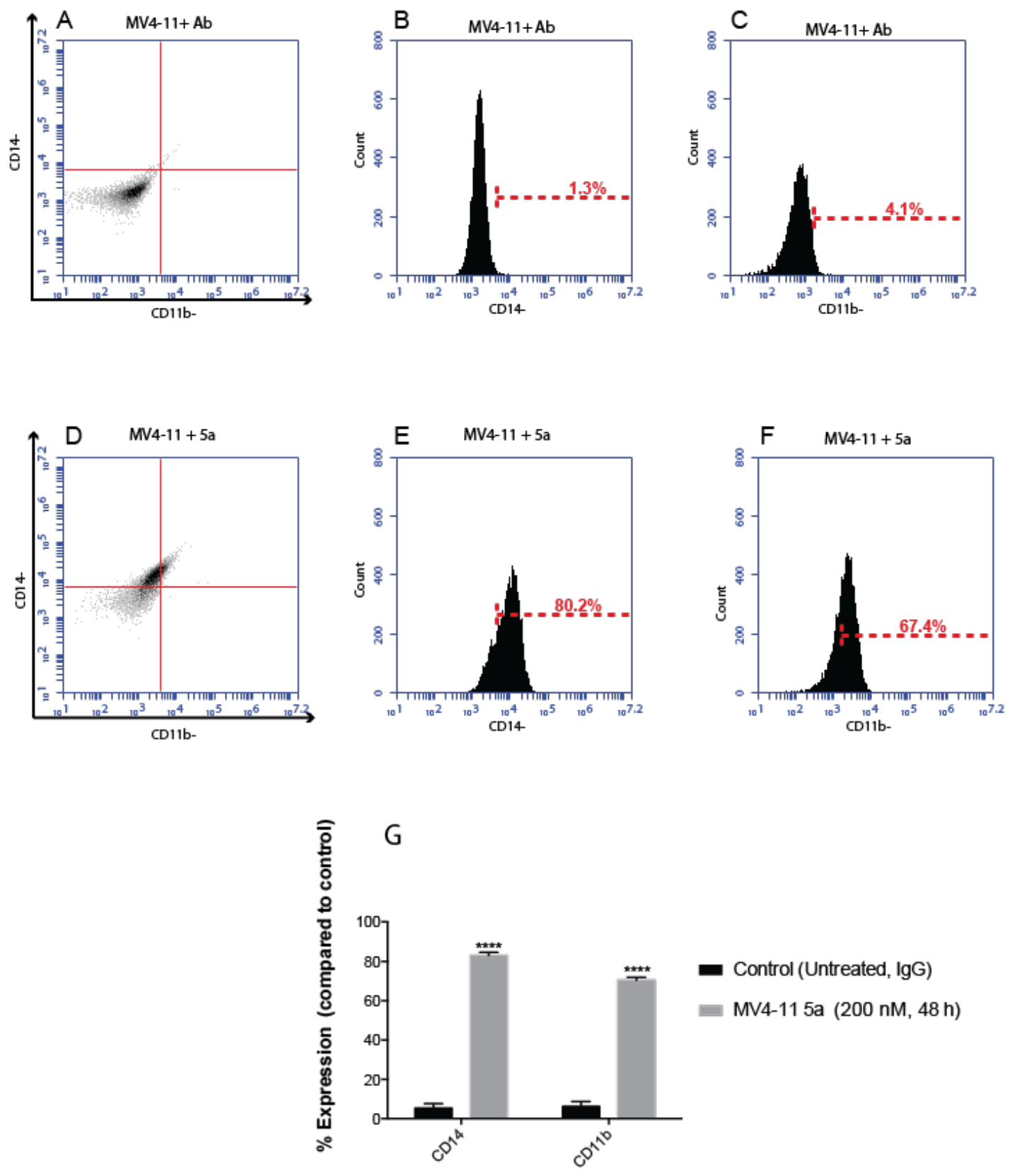
Figure 7. Effects of $5 \mathrm{~b}(200 \mathrm{nM}, 48 \mathrm{~h})$ on the expression of differentiation markers CD14 and CD11b in MV4-11 cells compared to control.

FSC and SSC profiles were applied for the initial gating by selecting cell size and distribution and remove cell debris. Plots A, B, C show the Isotype controls. Plots D, E, F show the experimental conditions. Plots A and D show the gated population: in the X-axis is reported the mean fluorescence intensities for FITC-CD14 Ab; in the Y-axis is reported the mean fluorescence increase for PE-CD11b Ab. Plots B and $\mathrm{C}$ (black histograms) report the fluorescence increase of Isotype controls (untreated cells); E shows the fluorescence increase of the monocytic marker CD14; F shows the fluorescence increase of the myeloid marker CD11b. Numbers shown in each box are the \% of cells expressing CD14 or CD11b. (G) Shown are results graphically summarised for three independent experiments. Statistical significance was determined with two-way ANOVA and corrected for multiple comparisons with Bonferroni's test. Values are expressed as means \% of CD14-CD11b increase $\pm \operatorname{STD}(\mathrm{n}=3) ; * * \mathrm{p}<0.001$.
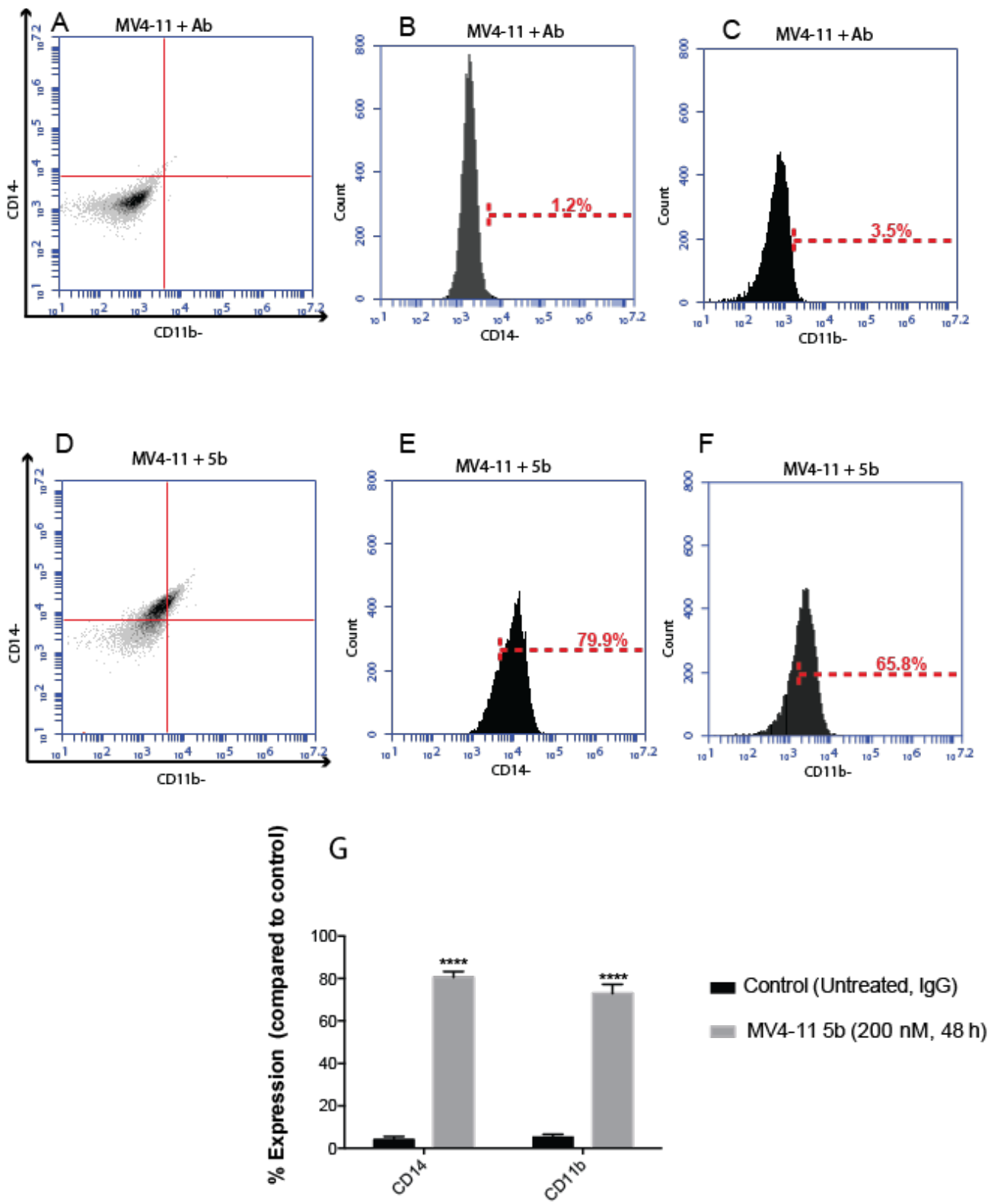
Table 4. Increase (\%) of CD14 and CD11b expression induced by 5a in AMLs (200 nM, 48 h). Results are expressed as \% of increase normalised to pre-treatment level (DMSO-vehicle control) \pm STD $(n=3)$.

\begin{tabular}{ccc}
\hline Cells line & $\begin{array}{r}\text { CD14 increase } \\
(\% \pm \text { STD }, \mathrm{n}=3)\end{array}$ & $\begin{array}{r}\text { CD11b increase } \\
(\% \pm \mathrm{STD}, \mathrm{n}=3)\end{array}$ \\
\hline U937 & $24.2 \pm 1.5$ & $94.2 \pm 1.2$ \\
HL-60 & $20.8 \pm 3.0$ & $68.3 \pm 11.8$ \\
OCI-AML3 & $69.7 \pm 12.3$ & $70.4 \pm 13.9$ \\
MV4-11 & $83.0 \pm 1.51$ & $70.4 \pm 1.5$ \\
KASUMI & $2.7 \pm 0.7$ & $17.9 \pm 3.5$ \\
THP-1 & $97.0 \pm 0.9$ & $93.6 \pm 5.3$ \\
\hline
\end{tabular}

Table 5. Increase (\%) of CD14 and CD11b expression induced by TCP derivative 5b in AMLs (200 nM, 48 h). Results are expressed as \% of increase normalised to pre-treatment level (DMSO-vehicle control) \pm STD (n=3).

\begin{tabular}{lll}
\hline $\begin{array}{l}\text { Cell lines treated with } \\
\text { 5b }(\mathbf{2 0 0} \mathbf{n M}, \mathbf{4 8} \mathbf{~ h})\end{array}$ & $\begin{array}{l}\text { CD14 increase } \\
(\boldsymbol{\%} \pm \mathbf{S T D}, \mathbf{n}=3)\end{array}$ & $\begin{array}{l}\text { CD11b increase } \\
(\boldsymbol{\%} \pm \mathbf{S T D}, \mathbf{n}=3)\end{array}$ \\
\hline & $14.1 \pm 0.9$ & $90.6 \pm 2.6$ \\
U937 & $29.1 \pm 4.7$ & $66.1 \pm 11.0$ \\
HL-60 & $84.4 \pm 5.6$ & $72.5 \pm 9.3$ \\
OCI-AML3 & $80.5 \pm 2.8$ & $72.9 \pm 4.4$ \\
MV4-11 & $3.8 \pm 0.1$ & $23.4 \pm 0.9$ \\
KASUMI & $97.1 \pm 1.2$ & $98.4 \pm 0.4$ \\
THP-1 & & \\
\hline
\end{tabular}


